\title{
INTEGRATED RENEWABLE HYDROGEN UTILITY SYSTEM
}

PHASE II FINAL TECHNICAL REPORT

PERIOD OF PERFORMANCE - MAY 2000 - OCTOBER 2002

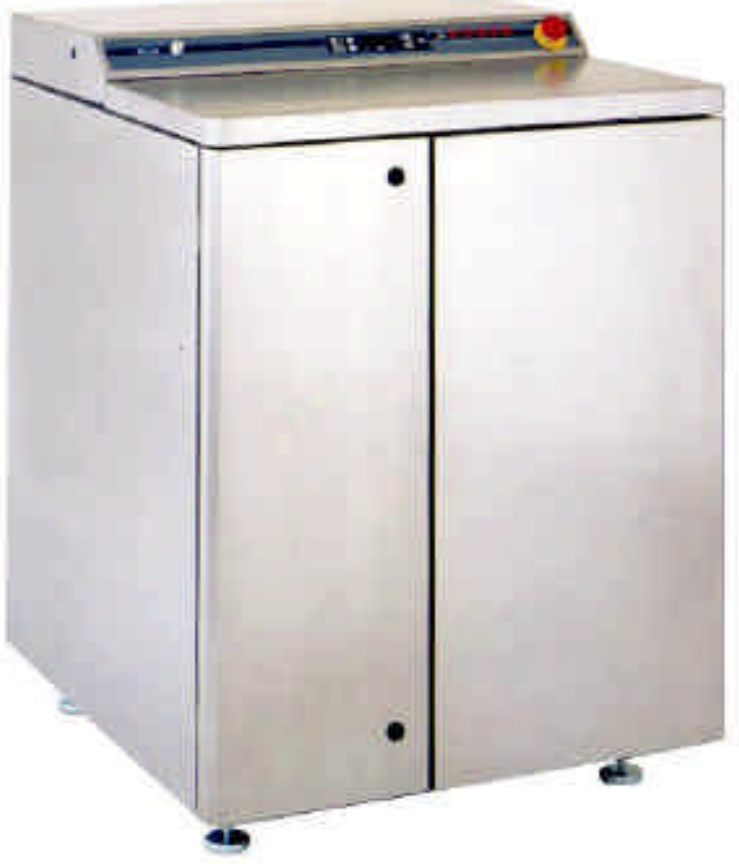

Robert J. Friedland

A. John Speranza

Proton Energy Systems, Inc.

10 Technology Drive

Wallingford, CT 06492

Date Published - February 2003

PREPARED FOR THE UNITED STATES

DEPARTMENT OF ENERGY

Under Cooperative Agreement

No. DE-FC36-98GO10341 


\title{
Author Contact Information
}

Mr. Robert Friedland

Principal Investigator

10 Technology Drive

Wallingford, CT 06492

Ph: 203-678-2144

Fax: 203-949-8078

Email: rob.friedland@protonenergy.com
Mr. A. John Speranza

Project Manager

10 Technology Drive

Wallingford, CT 06492

Ph: 203-678-2326

Fax: 203-949-8078

Email: john.speranza@protonenergy.com

\section{Acknowledgements}

The authors wish to thank all who have contributed to this project and in the preparation of this report. In particular, the author would like to thank the following Proton Energy Systems contributors:

\author{
Mr. Everett Anderson \\ Mr. Ryan Begin \\ Mr. Dave Christensen \\ Mr. Trent Molter \\ Mr. Angelo Morson \\ Mr. Lawrence Moulthrop \\ Mr. Norm Schaefer \\ Mr. Andy Stanek
}




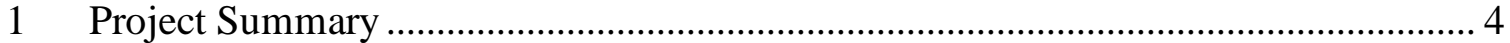

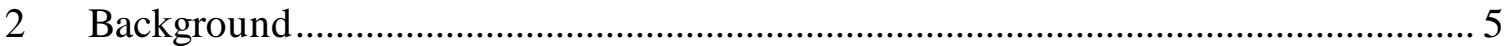

3 Power Electronics and Alternative Energy Interface ……………………………..... 6

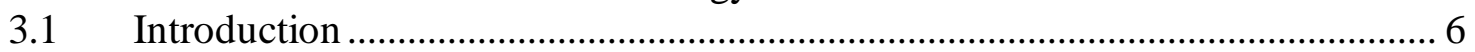

3.2 Power Electronics Cost Reduction.............................................................. 6

3.3 Alternative Energy Interface Converter........................................................... 11

4 Control Board Development............................................................................. 13

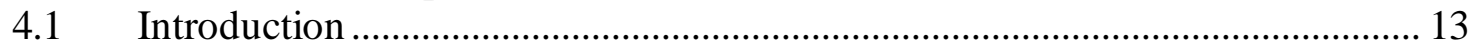

4.2 Control Board Functions .......................................................................... 15

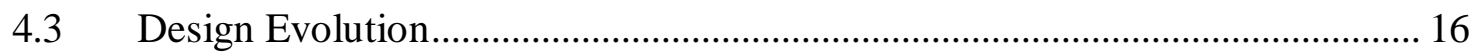

$5 \quad$ System Component Cost Reductions .................................................................. 17

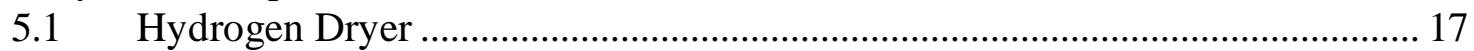

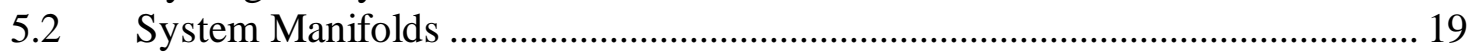

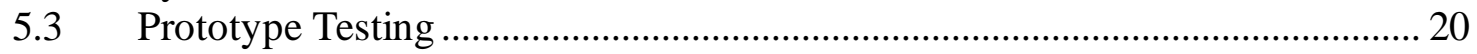

6 Electrolysis Cell Stack ……………………………………………………..... 20

6.1 Cell Stack Compression Hardware ………………......................................... 20

6.2 Reductions in Catalyst Loadings.................................................................. 22

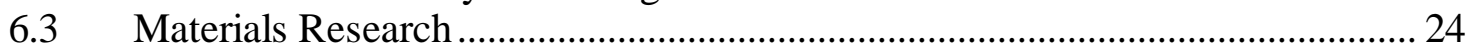

6.4 Statistical Variation Study ............................................................................ 25

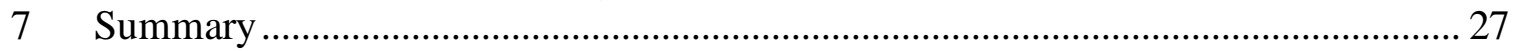

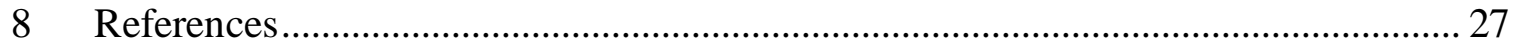

? HOGEN is a registered trademark of Proton Energy Systems, Inc. 
TDDR03001

February 2003

\section{Project Summary}

Products based on Proton Exchange Membrane (PEM) technology offer a unique solution to today's energy conversion storage needs. PEM products have undergone continual development since the late 1950's for many diverse applications. Rooted in rigorous aerospace applications, this technology is now "breaking away" to provide commercial solutions to common power, energy, and industrial gas feedstock problems. Important developments in PEM electrolyzers and various energy conversion devices (e.g. engines and fuel cells) can now be combined to form the basis for a revolutionary energy storage system that provides a much needed link to renewable resources, and offers a credible alternative for off-grid power applications. This technology operates by converting electrical energy into chemical energy in the form of hydrogen as part of a water electrolysis process when excess power is available. When the primary source of power is unavailable, chemical energy is converted into electrical energy through an external combustion heat engine or other energy conversion device.

The Phase II portion of this program began in May of 2000. The goal of Phase II of the project was to cost reduce the hydrogen generator as a critical link to having a fully sustainable hydrogen energy system. The overall goal is to enable the link to sustainability by converting excess renewable power into hydrogen and having that hydrogen available for conversion back to power, on demand. Furthermore, the cost of the capability must be less the $\$ 1,000$ per $\mathrm{kW}$ (electrical power into the generator) and allow for a variety of renewable technology inputs. This cost target is based on a production volume of 10,000 units per year.

To that end, Proton undertook an aggressive approach to cost reduction activities surrounding the $6 \mathrm{~kW}, 40$ standard cubic foot per hour (scfh) HOGEN? hydrogen generator. The electrical side of the system targeted a number of areas that included approaches to reduce the cost of the power supply and associated electronics as well as improving efficiency, implementing a circuit board to replace the discreet electrical components in the unit, and evaluating the system issues when operating the unit with a variety of renewable inputs. On the mechanical side of the system the targets involved creative use of manifolds to reduce components and plumbing, overall fitting reduction through layout simplification and welded tube assemblies, and the development of an inexpensive gas drying methodology to remove moisture and improve gas purity. Lastly, activities surrounding the electrolysis cell stack focused on lower cost stack compression approaches and cost reduction of critical components.

The last year of this project focused on validating the cost reductions mentioned above and advancing these cost reductions forward into a larger hydrogen generator. This larger hydrogen generator is a $60 \mathrm{~kW}, 380 \mathrm{scfh}$, HOGEN hydrogen generator. Most of these efforts were in the control board and manifold development areas.

The results achieved over the life of this program are in line with the goals of the Department of Energy. Proton projects that the current design of the $40 \mathrm{scfh}$ generator 
projected to a volume of 10,000 units per year would be in the range of $\$ 1,500$ per kilowatt. Furthermore, continuing efforts on materials substitution and design enhancements over the next few years should bring the cost of the system to the $\$ 1,000$ per kilowatt goal for a system of this size. This report provides the technical details behind the cost reduction efforts undertaken during the Phase II portion of the program.

\section{Background}

Since the inception of the Phase I portion of the program on April 15, 1998, Proton has successfully demonstrated a fully functioning integrated renewable hydrogen utility system in conjunction with STM Power at Arizona Public Service (APS) in Tempe, AZ. This system coupled a solar concentrating dish, an external combustion engine and a Proton HOGEN 300 hydrogen generator. The system was installed and operating from May of 1999 through the end of the Phase I program in December of 1999. A description of the technical performance of the system and a market assessment is detailed in the Final Technical Report ${ }^{1}$.

The Phase I demonstration efforts and market evaluation showed that a hydrogen generator coupled with some form of renewable power and some form of energy conversion device has a distinct advantage over a battery system backing up the same renewable application. Proton is not in a position to determine which renewable technology will win out in the end, nor can we predict which energy conversion device will be the most cost effective. However, it is clear that the link to these alternatives lies in the ability to convert excess renewable power into hydrogen and have the hydrogen available for conversion back to power, on demand.

To that end, Proton proposed a Phase II program that moved away from the solar concentrating dish effort and focused on cost reduction efforts aimed at the hydrogen generator family. The HOGEN 40 hydrogen generator was chosen as the model for these cost reduction efforts even though the HOGEN 300 hydrogen generator was used in Phase I of the program. This was done for two reasons. First, the smaller size of the HOGEN 40 hydrogen generator made cost reduction activities and hardware purchases less costly, and thus enabled a larger scope of effort and impact on return. Second, advances are scalable. In other words, improvements and cost reductions made on the HOGEN 40 hydrogen generator can be scaled to the larger HOGEN hydrogen generators with less financial and programmatic risk. The specifics of this proposal were outlined in the Technical Paper submitted for the 2000 annual review ${ }^{2}$. 
TDDR03001

February 2003

\section{Power Electronics and Alternative Energy Interface}

\subsection{Introduction}

The goal for the power electronics and alternative energy interface task was to look for innovative ways to reduce the cost of the electrolysis cell stack power supply and associated electronics as well as improving its efficiency. Rectifiers that are most commonly used for converting AC into DC for electrolysis, in general, represent about $10-15 \%$ of an electrolyzer's total system material cost. Work in the early stages of the program was focused on integration of many of the discrete components of the power electronics design into one system in order to eliminate redundant framework and components. Subsequent phases of the program focused on better understanding the load characteristics of the electrolysis cell stack and optimizing the power electronics package. As a result of this program, an order of magnitude cost reduction of power electronics optimized for electrolysis has proven to be achievable.

Power electronics also plays a significant role in overall electrolyzer system efficiency. Therefore an improvement in power conversion efficiency is key to achieving the optimum cost per cubic foot of hydrogen produced. The efficiency study that was conducted in the early stages of the program along with the load characterization study that was conducted, have resulted in an optimized power electronics design that promises to deliver a significant improvement in efficiency. Traditionally electrolyzer power electronics efficiencies have been in the $85-90 \%$ range. As a result of this program efficiencies greater than $90 \%$ have proven to be achievable.

It is imperative that electrolyzers be able to ultimately interface directly with a number of different renewable energy technologies. Significant work has been done to advance the state of power electronics that are designed specifically to connect directly to renewable energy sources of power. The design focus in the early stages of the program was to interface the HOGEN hydrogen generator directly to a DC source of power. Both cost and efficiency were considered when making design choices during this stage, but were not a significant driver. As the program progressed more importance was placed on cost and efficiency of the design. This ultimately resulted in an approach that promises to be at similar cost levels to the utility grid connected converter.

\subsection{Power Electronics Cost Reduction}

The initial effort on this task was intended to accomplish a full investigation of the power conditioning technologies that would be viable for the utility grid connected HOGEN 40 hydrogen generator series product. The power conditioning technology that has been utilized in the HOGEN 40 hydrogen generator to date has been high frequency switch mode technology. High frequency switch mode converters are generally very compact, exhibit a high power factor, and are relatively efficient. However, the cost of the technology is approximately $\$ .35 /$ watt and does not readily lend itself to cost reduction. Investigation of several alternatives led us to Sustainable Energy Technologies (SET) which developed a prototype $9 \mathrm{~kW}$ power supply that had a cost of $\$ 1,500(\$ .16 / \mathrm{watt})$ at a 
quantity of 500 units. Our goal at this point in the program was to develop a power conditioning module that represented a technically equivalent alternative to the higher cost switch mode power conditioning module at less than $\$ .15 /$ watt. The successful testing of the prototype unit provided by SET allowed us to prove that the goal was achievable.

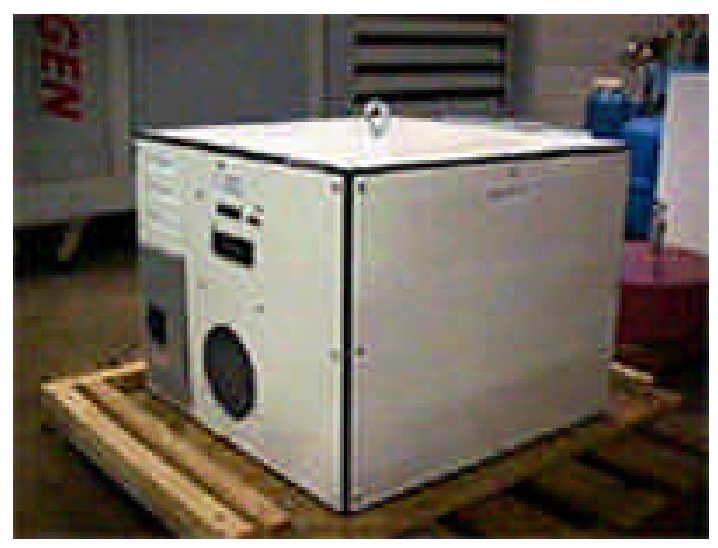

Figure 3-1 - SET Prototype Low Cost Power Conditioner

The only drawback to this prototype was the overall size (32" x32" x32"), which was significantly larger than the envelope of the switch mode supplies (5.5" $\times 5.5$ " 15 "). This size makes integration into the present footprint impossible and would result in two separate modules. Thus, some of the savings could be reduced by added cost to interface these two separate boxes. Further development of the concept continued with SET to work on envelope versus cost. SET delivered a power electronics package that was significantly smaller (10"x18" x24"), but still larger than the switch mode supplies, and met the cost targets with higher volumes of $>1000$ units. Testing of this prototype was initiated and the unit failed shortly thereafter due to an internal short that rendered the device inoperable. Unfortunately, the cost of repair was prohibitively expensive and it was determined that the testing be terminated. Due to the premature failure of the device, testing beyond the initial power tests was never conducted and therefore, power quality and efficiency measurements were never verified.

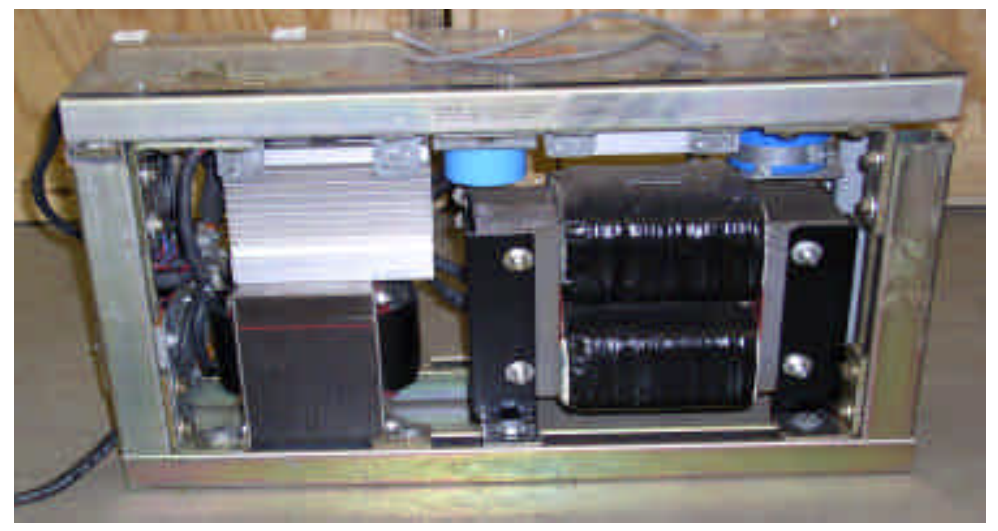

Figure 3-2 - Power Converter 
A feasibility and design study based on the power electronics cost reduction effort for the HOGEN 40 hydrogen generator was conducted. The study concluded that the high cost of power conversion on these units is due mainly to two factors, buying an "off the shelf" design that is not optimized for the electrolysis application and the requirement of galvanic isolation between the power source and the electrolysis cell. Another important finding made during the study was the capability of the electrolysis cell to absorb significant line frequency ripple current. This allows for a significant reduction in the energy storage required in the converter, thus further reducing the overall cost of the converter. This analysis was explained in detail in the peer review paper from $2002 .^{3}$

Due to the initial results of the feasibility study, it became evident that the path to the lowest cost for power electronics is in a design that is optimized for the electrolysis process and the only way to accomplish this is to develop a specific design for that purpose. It was decided to initiate a preliminary design effort focused on the design and cost analysis of a modular "power board" designed specifically for use with our electrolyzer platform.

The design path that was chosen was the utilization of a single power converter module that included input isolation and a small amount of energy storage on the front end and would be used as a modular component in a flexible power package. The inclusion of input isolation was a diversion from the results of the feasibility study conducted earlier in the year due to the fact that the cost benefits would be nullified by the fact that extra hardware would be required to insure safety. The key cost benefits of the preliminary design were primarily based on the modular circuit board approach.

The module would provide a programmable current output of up to $83 \mathrm{ADC}$, with a voltage output range of 10-90V. Each module would have front end isolation provided by an input rectifier and EMI filter, phase shift bridge converter, output transformer, rectifiers and filtering, current feedback control, and protection circuits. Each module would be rated for approximately $8 \mathrm{~kW}$ and would provide a series/parallel building block for a range of electrolyzer outputs. The board would be used in a card cage, which would provide the necessary input and output connections, main control, and adequate air for cooling. The design concept would support 3 phase AC operation, $480 \mathrm{~V}$ or $240 \mathrm{~V}$ depending on the input connections.

The modular design would allow for expandability to the multi-kW electrolyzers utilizing a small common module, thus taking advantage of volume manufacturing and commonality of parts across a product platform. Also, due to the fact that the design is a circuit board component it can take advantage of circuit board manufacturing techniques such as pick and place, wave soldering, and surface mount technologies. The estimated cost for this power electronics platform in modest quantities is below $\$ .05 /$ watt at the $8 \mathrm{~kW}$ module level and much better at the multi-kW rack level due to the increase in required volume components. 


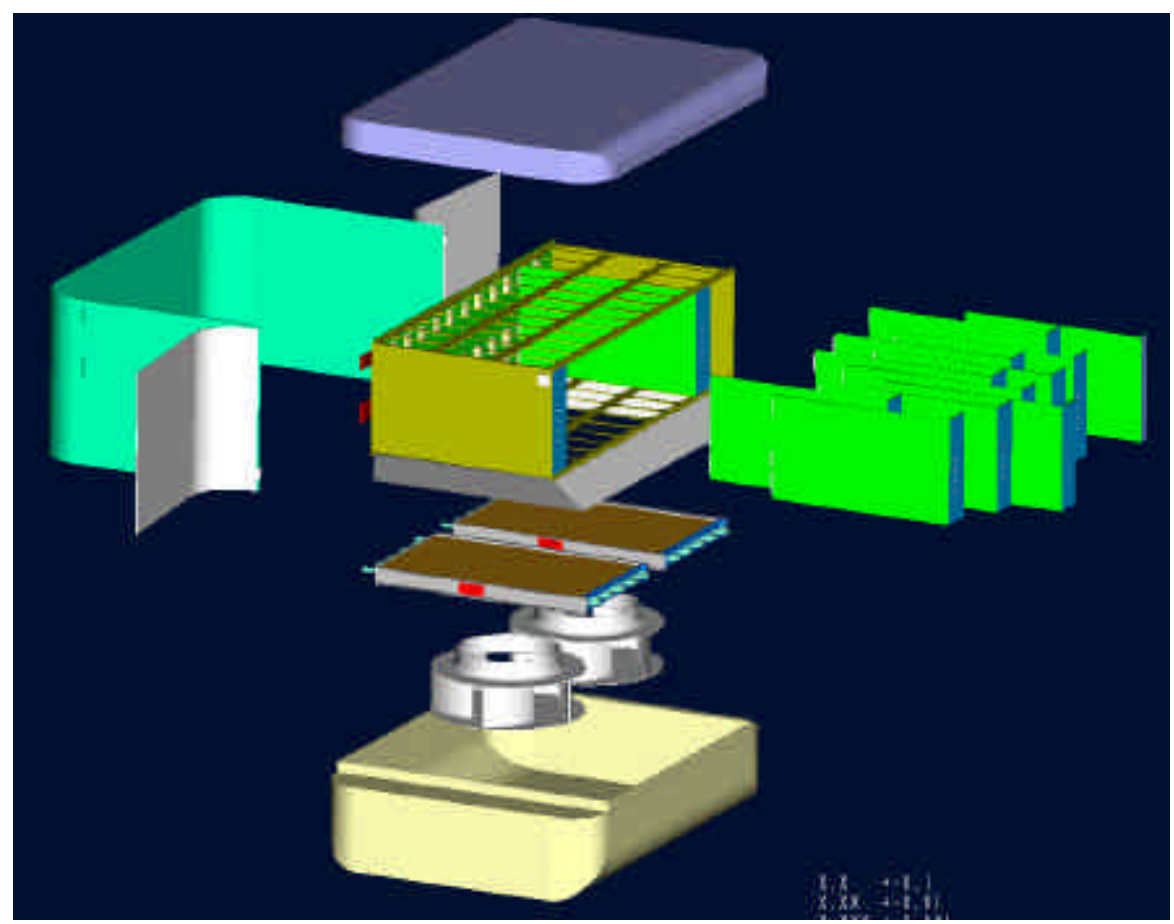

Figure 3-3 - Exploded View of Proposed Power Electronics Platform 


\section{Modular Power Converter Preliminary Specifications}

Input

1. Input Voltage Range

400, 440, 480 VAC ? 10\% Three Phase (360-528 VAC ph-ph)

200, 220, 240 VAC ?10\% Three Phase (180-264 VAC ph-ph)

(input connector jumper selectable)

2. Frequency - 47-63 Hz

3. Power Factor - Minimum 0.8

Output

1. Current - 0-83.3 Amps, Programmable

2. Current Regulation - 0? 5V program gives 0 ? $83.3 \mathrm{~A}$ nominal

3. Voltage Compliance Range -10-90V

4. Voltage Regulation -95V?5V initial setpoint

5. Power - $8.3 \mathrm{~kW}$ maximum

6. Minimum Load - Not Required

7. Turn-On Delay - 2 seconds maximum from the application of AC line

Protection Circuits

1. Over-Voltage

101-112 VDC Latching shutdown. Turn off AC line for 5 seconds

to reset, maximum of 3 times. Sensed at output terminals.

2. Over-Temperature - Automatic shutdown. Resume operation at normal temperature.

3. Short Circuit - Maximum 88-96A limit. Power supply shutdown.

Controls and Monitors

1. System Monitors- report to motherboard

a. Open Fuse

b. Over Voltage

c. Over Current

d. Over Temperature

e. Over Input Voltage

2. Enable - 20-28VDC to run, open to stop

3. Current Program

0 ? $5 \mathrm{~V}$ program gives 0 ? $83.3 \mathrm{~A}$ ?2A No trickle current at zero. DC galvanic isolation. Linear control. (Note- source $\mathrm{Z}$ is $2 \mathrm{k}$ )

4. Current Monitor

0 ? 83.3A output gives 0 ? $5 \mathrm{~V}$ ?0.125V. DC galvanic isolation.

Low pass filtered. (Note- design to drive 20k)

5. Voltage Monitor

0 ? $100 \mathrm{~V}$ output gives 0 ? $5 \mathrm{~V}$ ? $0.125 \mathrm{~V}$. DC galvanic isolation.

Low pass filtered. (Note- design to drive 20k)

Environmental

1. Temperature

a. Operating: -29 to $+70 \mathrm{C}$

b. Storage: -40 to $+60 \mathrm{C}$

2. Humidity - $20 \%$ to $100 \%$, non-condensing

3. Altitude - Operating: 8,000 feet

4. Shock - Non-Operating: $30 \mathrm{G}$, half sine

5. Cooling - 200 SCFM airflow minimum, at 70C maximum

Agencies/Safety

1. EMC

Designed to meet EN55011:1998 Group I Class A and EN61000-6-2:1999 When integrated into system.

2. Safety

(Test Reports not required.)

Designed to meet UL508, UL1012, EN50178, and EN60742.

(A declaration of conformity is necessary for EN50178 and

EN60742.)

MTBF

1. Design for $88 \mathrm{khrs}(10 \mathrm{yr})$ lifetime continuous duty

? HOGEN is a registered trademark of Proton Energy Systems, Inc. 


\subsection{Alternative Energy Interface Converter}

Numerous developers overlook, or fail to fully understand, the difficulty in interfacing different types of renewable energy technologies with PEM electrolyzers. Early in the program Proton identified Sustainable Energy Technologies (SET) as a premier developer of high efficiency low cost power electronics suitable for interconnection with renewable energy sources. Proton contracted with SET to develop a universal renewable energy interface converter that would couple a DC renewable energy source directly to a HOGEN 40 hydrogen generator. In addition, Proton started working with the Illinois Institute of Technology (IIT) on an overall system integration task combining a HOGEN 40 hydrogen generator, with a photovoltaic array and a fuel cell. This full- scale demonstration was designed to provide valuable real world data on complete system architecture. The renewable interface was designed to take a $5 \mathrm{~kW}$ PV or Wind input with a wide input voltage range and utilize full maximum power point tracking algorithms to deliver a current controlled output to the electrolyzer for hydrogen production and storage.

A HOGEN 40 hydrogen generator was shipped to IIT and was fully functional on grid power on June 15, 2001. The SET renewable interface was shipped to IIT for integration and testing with a $2.6 \mathrm{~kW}$ PV system. Figure 3-5 below illustrates a typical renewable power system that might be utilized for small village or remote telecommunications applications. Demonstrations like the one at IIT help to make clear that the only long term viable path to sustaining a renewable grid is through electrolysis and high pressure hydrogen storage. Integration of the generator to the grid has been completed and testing and familiarization of the generator and fuel cell device has been ongoing. There have been some technical and manpower delays with respect to integration of the photovoltaic system and Proton as well as SET are working with IIT to keep the project moving forward. While full system testing was not completed during the program, the data and integration insight gained from this collaborative project will be invaluable to understanding the issues associated with designing, deploying, and maintaining renewable systems for a variety of applications, and will certainly be integrated to design efforts going forward. 


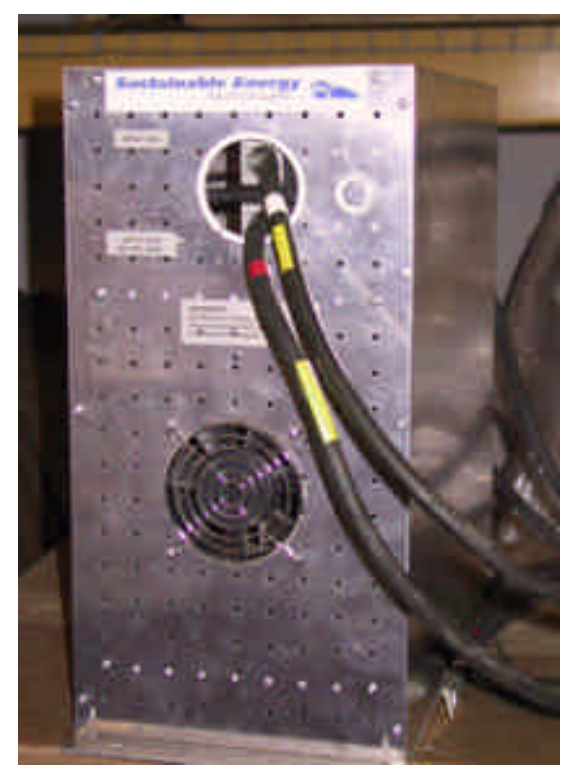

Figure 3-4 - Renewable Energy Interface Converter

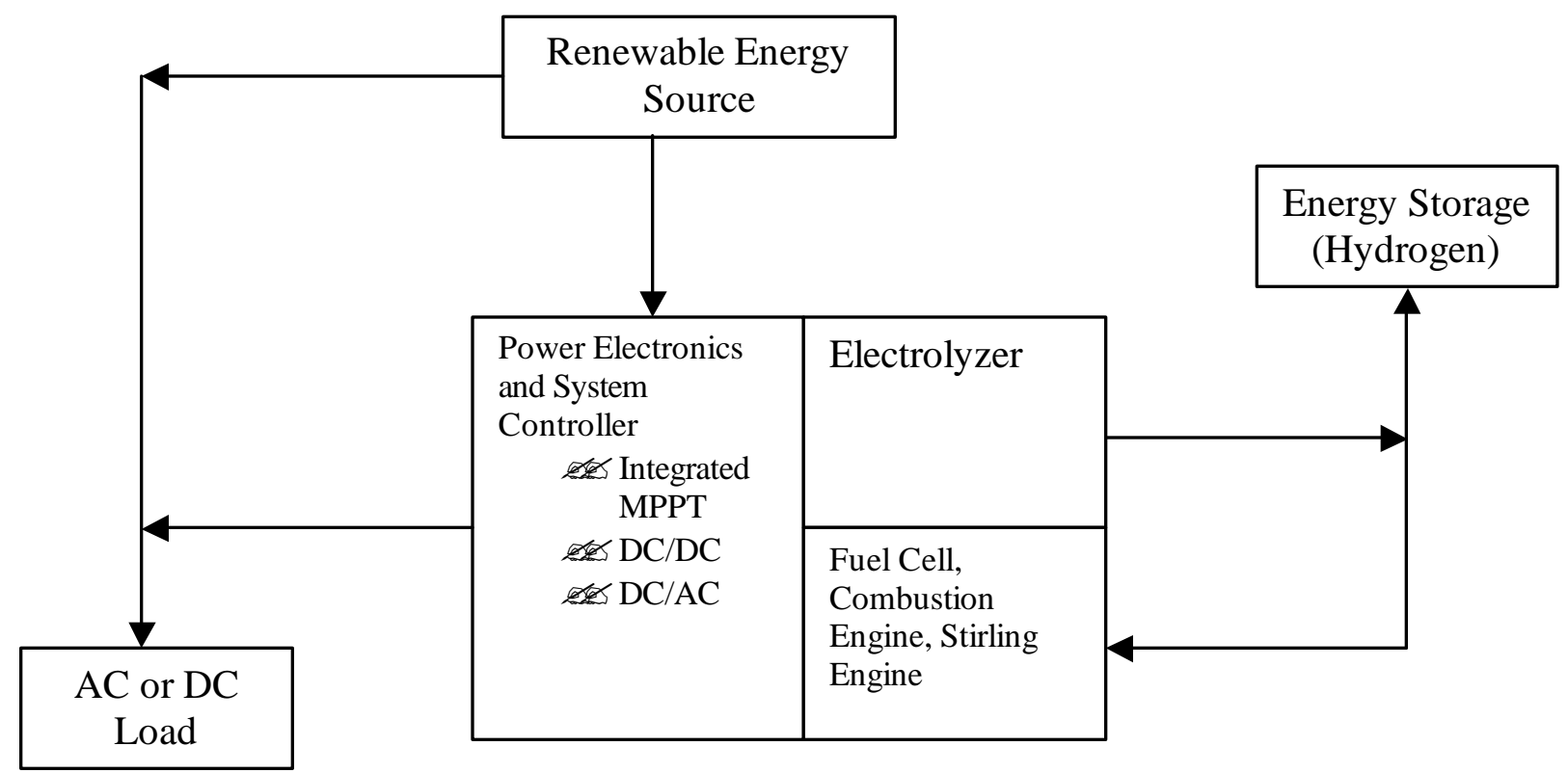

Figure 3-5 - Typical Renewable Power System

The integration of renewable energy technologies with Proton's hydrogen generators is crucial to enabling renewable energy sources to integrate seamlessly with the existing energy infrastructure. The power electronics interface to those renewable energy technologies plays a key role in realizing that seamless integration. To that end, Proton initiated a preliminary design study task in conjunction with our utility grid converter cost reduction effort to design a "power board" module that would integrate into the utility grid converter power rack. The design path that was chosen was the utilization of a 
single power converter module that would be used as a modular component in the flexible power package that was being developed for the grid connection design discussed earlier. The design of the DC/DC power module would take advantage of the same key cost benefits of the modular circuit board approach as the grid converter.

The module would provide a programmable current output of up to 83 ADC, with a voltage output range of $10-90 \mathrm{~V}$. Each module would be rated at $8 \mathrm{~kW}$ and would provide a series/parallel building block for an expandable electrolyzer platform. The DC/DC power board would be used in a card cage along with AC/DC power boards to provide a hybrid system, or alone for a completely grid independent approach. The card cage would provide the necessary input and output connections, main control, and adequate air for cooling. This modular approach would take advantage of the same benefits as the AC/DC design discussed previously and offer similar \$/watt estimates.

\section{Control Board Development}

\subsection{Introduction}

The HOGEN 40 hydrogen generator has historically utilized a number of discreet electrical control components to provide the architecture behind the control system (See Figure 4-1). This approach was invaluable early in the history of this design because it readily lent itself to changes and improvements as the design was evolving. A custom designed control board was developed to provide functional improvements above the capabilities of the discreet component approach and to significantly remove cost from the unit. The compact 5.5" x 14" size of the board also helped minimize packaging efforts and freed up space in the box for thermal management and other needed system functionality. The overall benefit realized from this effort was a material savings of approximately $\$ 1,500$ and a labor savings of approximately 40 hours in the assembly of the system (See Figure 4-2). The design was further developed to increase the functionality and size to accommodate the HOGEN 380 hydrogen generator. That effort was developed and testing completed on a pre production version of the board. Cost savings on this version are even more dramatic where over $\$ 12,000$ of material cost and 100 hours of wiring labor were eliminated. 


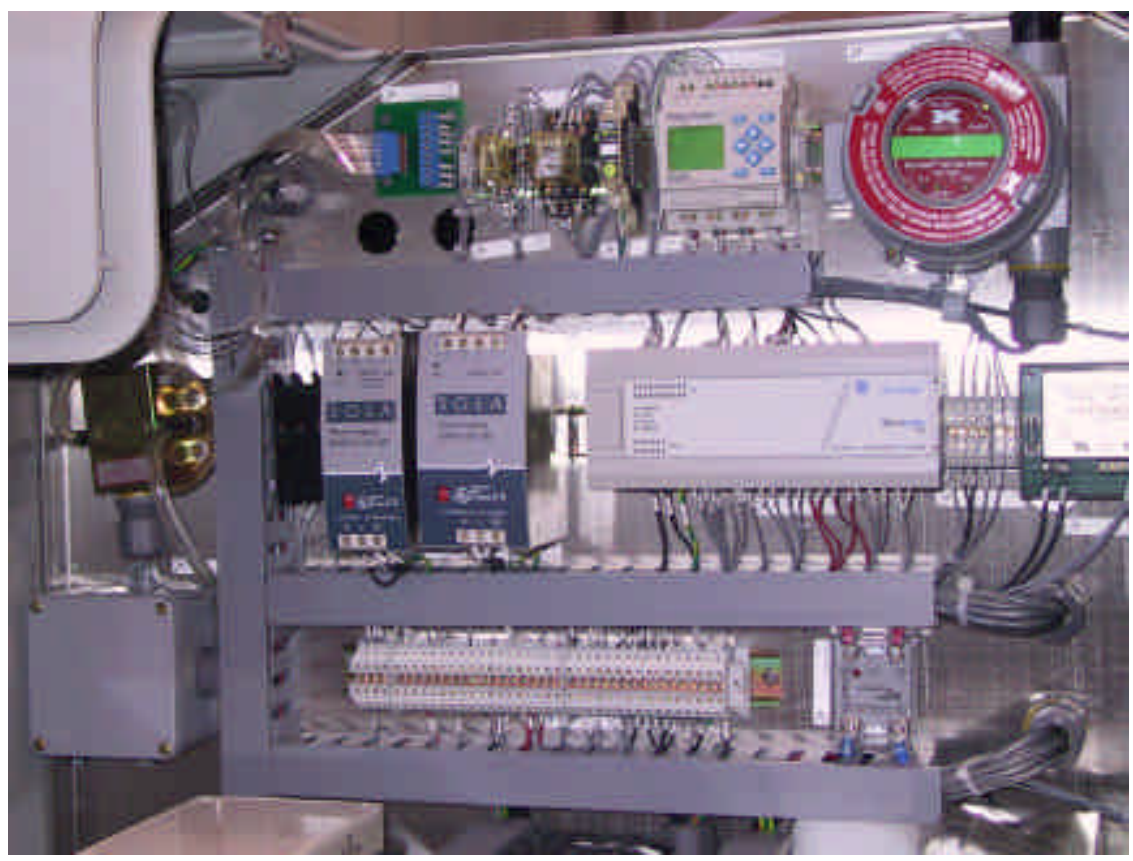

Figure 4-1 - Discreet Component Control System

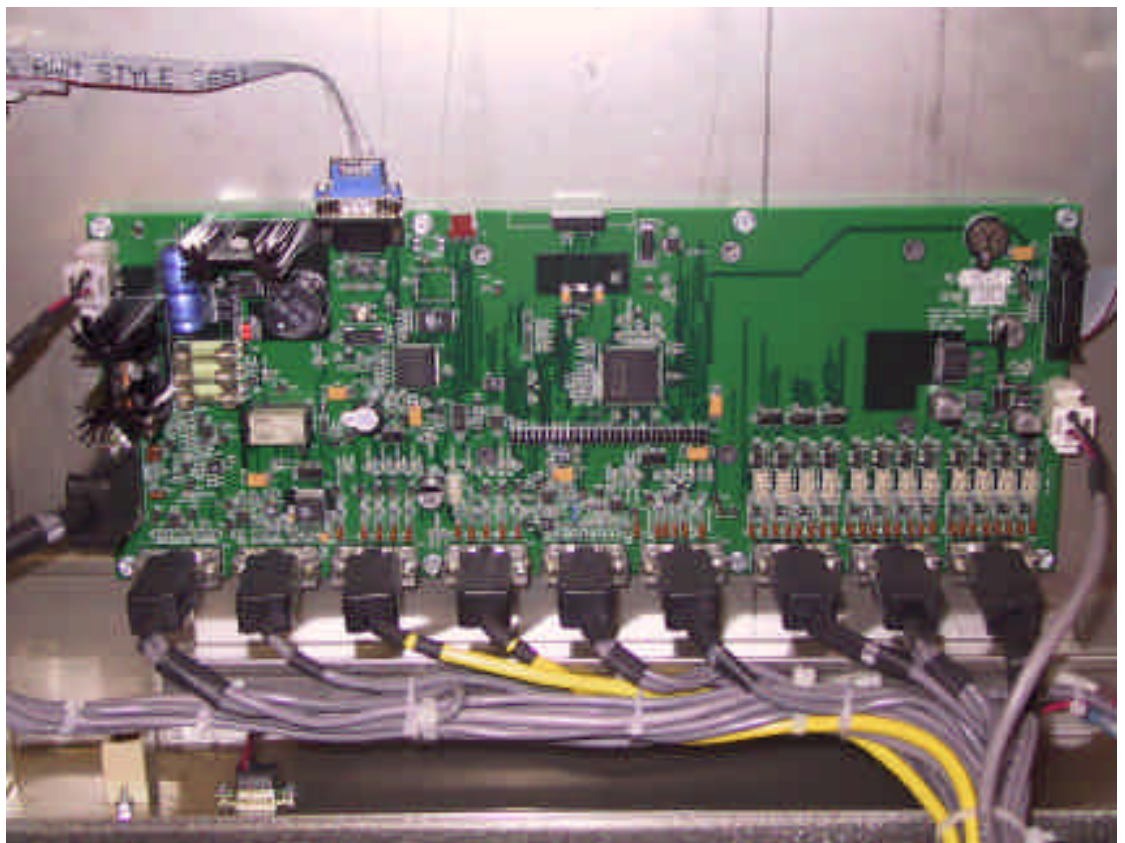

Figure 4-2 - Control Board 


\subsection{Control Board Functions}

The HOGEN 40 hydrogen generator control board was designed with the following basic functionality for system level control:

?? Pressure sensing and control

?? Combustible gas detection

?? Water flow detection

?? System temperature monitoring

?? Cell stack current control

?? Fluids management through water level control

?? Water quality detection

?? Gas drying control

?? Operator display and shutdown controls

In addition to these basic controls, the board was also designed with various software capabilities and configurable parameters to allow greater system flexibility and enable quick configuration changes to the system. These parameters include:

?? Selectable operation - tank filling or load following

?? Operating product pressure set point

?? Variable sizes of electrolysis cell stacks

?? System de-rating and current limiting

?? Various shutdown limits

?? Gas calibration interval

When the board was evolved into the HOGEN 380 hydrogen generator many of the monitoring functions were expanded into control functions due to the increased complexity of the system and increased amount of gas produced. These enhancements included:

?? System temperature control for a wider range of operating environments

?? Water purification control of on-board water purification system

?? Expanded list of warning levels in excess of basic shutdowns

?? Expanded de-bug and monitoring modes

?? Cell stack health monitoring

As the HOGEN hydrogen generator product family develops further into renewable and fueling applications, combinations of this board level functionality can be easily combined and fine-tuned to best suit the specific application with little or no cost impact on the final design of the product. 


\subsection{Design Evolution}

With the basic functionality of the HOGEN 40 hydrogen generator control board described above reduced to a specific design specification, the design and testing process was initiated. The board went through extensive testing to ensure that it would be compatible with international and domestic safety standards. Figure 4-3 shows the matrix of testing that the board was subjected to as well as the standards it needed to meet.

\begin{tabular}{|c|l|l|}
\hline \multicolumn{1}{|c|}{ TEST } & \multicolumn{1}{|c|}{ STANDARD } & \multicolumn{1}{c|}{ NOTES } \\
\hline Highly Accelerated Life Testing & & \\
\hline Temperature & T0002436 & Tested by Qualmark \\
\hline Vibration & T0002436 & Tested by Qualmark \\
\hline Agency Certifications & & \\
\hline Safety & & Tested by TUV Rheinland \\
\hline NTRL-US (UL) & UL3111, UL3101 & Tested by TUV Rheinland \\
\hline NTRL-CANADA (CSA) & C22.2 No. 1010 & Tested by TUV Rheinland \\
\hline CE & EN60204 & \\
\hline EMC & & Tested by TUV Rheinland \\
\hline CE & EN50081, EN61000 & \\
\hline Operational Testing & & Proton Validation Testing \\
\hline Hardware & VT-2002-0005 & Proton Validation Testing \\
\hline Firmware & VT-2002-0005 &
\end{tabular}

Figure 4-3 - Control Board Validation Matrix

In addition to rigorous testing internally to verify functionality and control of the system, the Highly Accelerated Life Testing (HALT), per the specifications indicated above, subjected the control board to Thermal Step Cycling from +110 ?C to -60 ?C and Vibration Step Cycling up to 50G. The board performed very well during these tests as well as the ones listed in Figure 4-3 above and the amount of changes required to the design were minor and easily corrected.

This design and all of the lessons learned then became the jumping off point for the design of the HOGEN 380 hydrogen generator control board. To maximize effectiveness the HOGEN 380 hydrogen generator controller was built off of the platform generated by the HOGEN 40 hydrogen generator product team. Developing a daughter board scheme allowed a very low cost alternative to developing a unique platform. It also gave the design team the ability to expedite testing to prove system functionality. Since the restructured controller incorporated the HOGEN 40 hydrogen generator controller and the daughter card scheme, the board architecture was also upgraded. The restructured board utilizes 5-output analog signals, 50-output digital signals, 23-input analog signals and 7-input digital signals. Ten percent of the total inputs and outputs are built in as spares to compensate for any required future growth. 
The control board also provides an output to a digital display for parameter viewing, user control and error code display. The digital display is a 4-digit 7-segment display with the ability to display five different parameters during normal operation; system pressure, product pressure, hydrogen flow rate, system temperature, stack health, and product flow. The display area also has an indication of engineering units in use, with a momentary switch adjacent to the indicator to toggle between the units. The momentary switches incorporate indicators adjacent to the display to toggle between system pressure and product pressure. Up and down arrow keys are utilized to increment and decrement display values. The display is further used to enter and monitor several system operation modes for troubleshooting and maintenance.

As a safety precaution all shutdown parameters are monitored on a continuous basis after the system has been powered up. All shutdowns result in no current to the electrolysis cell, all outputs de-energized, an error code on the display, and the need to reset the system before continuing operation.

\section{System Component Cost Reductions}

\subsection{Hydrogen Dryer}

In PEM -based water electrolysis systems, water vapor is the only impurity of significance in the product hydrogen gas stream. Cost-effective techniques for removing that water are paramount to a reliable and robust design. Initially, the hydrogen gas generated inside the PEM stack is saturated with water vapor at the process temperature.

The concentration of water vapor in the hydrogen can be expressed as the ratio of the partial pressure of water to the total gas pressure. (A partial pressure of 1 psi water vapor in 100 psia hydrogen results in a water vapor content of $1 \%$ or 10000 parts per million ) Since PEM electrolyzers have the ability to make hydrogen gas at elevated pressures, it stands to reason that there is an order of magnitude reduction in water vapor concentration as generation pressures increase from one atmosphere to ten atmospheres. As the hydrogen generator designs have evolved and the application specific requirements for purity and dryness levels of the gas have developed, the tradeoff between the costs of increasing the generation pressure of the gas and balancing the dryer solution are constantly debated.

Purity levels of hydrogen gas are measured in various ways in the industry. Some use purity percentages, others use dew point and still others use parts per million (ppm) measurements. Figure 5-1 summarizes a few of the measurement points.

\begin{tabular}{|c|c|c|}
\hline Dew Point & Purity as a \% & PPM \\
\hline -61?C & 99.999 & 10 \\
\hline -76?C & 99.9999 & 1 \\
\hline <-90?C & 99.99999 & .1 \\
\hline
\end{tabular}

Figure 5-1 - Purity Measurements (at STP) 
The starting point for hydrogen drying was the use of a palladium style purifier that does a very effective job of removing moisture and achieving purity levels of .1 ppm or better. The issues with this drying technique are simply cost. A palladium purifier for the HOGEN 40 hydrogen generator costs approximately $\$ 7,500$. In addition, it operates at temperatures above 300?C requiring additional cost for insulation. Lastly, from the market side, very few customers actually require purity levels down to the $.1 \mathrm{ppm}$ level so additional incentive existed to find alternative means of drying the hydrogen gas.

A more traditional approach to gas drying is through pressure swing adsorption (PSA). Typically, several packed columns are used in a PSA design. The wet gas is passed through a working column filled with a desiccant material to remove the moisture from the gas stream. After the working column removes moisture from the product gas stream, a portion of the dry gas is expanded through an orifice and passed through the previously used column to dry it out (regeneration). An arrangement of valves and timing controls causes the drying and regeneration processes to cycle between the columns. Many companies make these types of dryer typically for large industrial applications or smaller scale laboratory applications. In addition, the number of dryers produced of any one variety is relatively small so the cost of the unit is still a concern. The other aspect about this technology is in the purity levels that can be achieved. PSA dryers will typically achieve purity levels approaching $5 \mathrm{ppm}$. Several styles of commercially available PSA dryers were tested and uncovered several problems. First, there was not an exact match of dryer designs with our flow rates of $40 \mathrm{scfh}$, pressure levels (200 psi), and starting moisture levels of the gas so most of our tests were conducted with non-ideal designs. Second, these commercial PSA dryers, originally designed to dry air, used up to $20 \%$ of the input hydrogen gas stream to regenerate. This high purge rate results in a large output penalty in the amount of actual gas the unit could deliver to the customer. Finally, the cost of these units, while lower than the palladium purifier, was still close to $\$ 3,000$. The target cost we set out for in relatively low volumes was under $\$ 1,000$.

This led to advancing an internal design effort that had been previously started on an internally funded R\&D project. This internal effort had developed a discreet component PSA sized for the specific output of the generator. This effort was to take that design, which was still projected at double the target cost, and look for ways to reduce the cost. This design used a two-column PSA with the valve mechanisms located on the top and bottom in a manifold approach (See Figure 5-2 below). The target specification on the dryer was to reduce the water content of the gas stream from $60,000 \mathrm{ppm}$ to $<5 \mathrm{ppm}$. The other benefits of this design were that eight individual components plus twenty-six fittings were manifolded into one subsystem. The electronic controls, which were a separate control box, were incorporated into the control board as described earlier. The overall envelope was reduced significantly and most of all the cost was reduced to the target cost of under $\$ 1,000$. Work was performed to accurately size the regeneration stream flow control orifice for hydrogen at the 200 psi inlet condition, resulting in an improved $10 \%$ purge loss rate. 


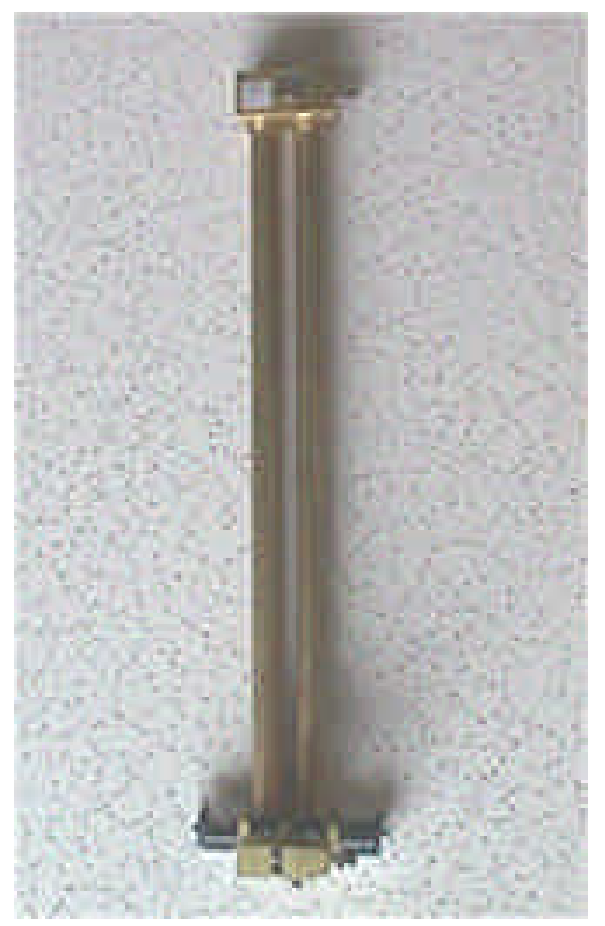

Figure 5-2 - Pressure Swing Adsorption Dryer

\subsection{System Manifolds}

The manifolds used on the PSA dryer were one example of cost reductions through manifolding of components. This same technique was used on the hydrogen and oxygen phase separators for the HOGEN 40 hydrogen generator and then carried forward to the larger HOGEN 380 hydrogen generator. This has had a tremendous benefit in terms of component costs, numbers of fittings, reduction of potential leakage pathways through reductions in fittings, and ease of installation in the final product. Figures 5-3 and 5-4 below show an example of the number of components combined into a manifold.

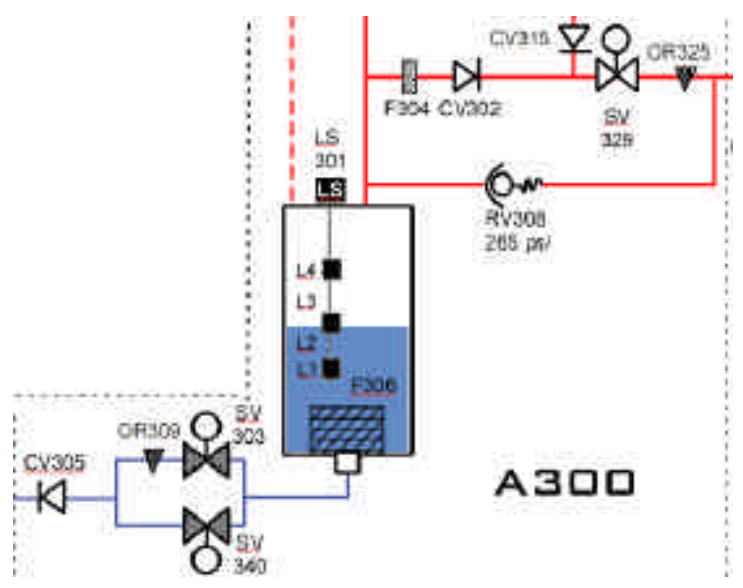

Figure 5-3 - Schematic of Phase Separator 


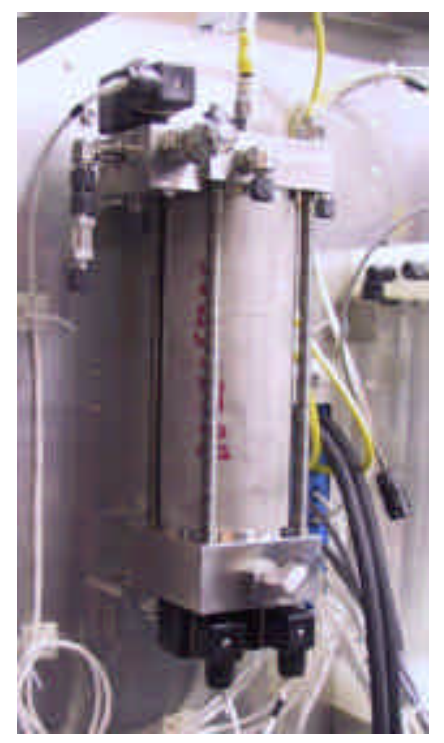

Figure 5-3 - Manifolded Phase Separator

The benefits of this approach were certainly evident in the cost reductions where over $50 \%$ of the cost was removed taking into account both material, as well as assembly and test labor. Lastly, this approach lends itself to further cost reductions through castings and/or forgings as volumes warrant the investment in capital tooling.

\subsection{Prototype Testing}

All of the component concepts were tested in a prototype box to validate that each of the changes were capable of meeting the rigorous standards that the HOGEN hydrogen generators are subjected to. The testing of these components showed no negative complications associated with the reconfiguration of the discreet components into manifolds.

\section{Electrolysis Cell Stack}

\subsection{Cell Stack Compression Hardware}

PEM electrolysis cell stacks have had a long history using small diameter disk springs on individual tie rods to provide a clamping mechanism that would maintain compression within the cell stack as the stack ages and experiences mechanical creep. While this has been a highly reliable design, the cost to handle the large number of parts is prohibitive. In addition, the need for a significant stack up of these spring washers increases the overall envelope of the cell stack and limits the flexibility in packaging the stack. To solve this problem a large spring washer configuration was developed to simplify the overall approach. Figure 6-1 shows the different configurations. 


\begin{tabular}{|c|c|c|c|}
\hline Current Hardware & Item & Component & Purpose \\
\hline \multirow{2}{*}{$\begin{array}{c}\text { Next Generation } \\
\text { Hardware }\end{array}$} & 2 & $\begin{array}{c}\text { Small Diameter Disk } \\
\text { Springs }\end{array}$ & $\begin{array}{c}\text { Compensate for reduction in } \\
\text { Springs }\end{array}$ \\
\cline { 2 - 4 } & 3 & Alignment Bearing & $\begin{array}{c}\text { Center alignment and hard contact } \\
\text { of cell sealing materials } \\
\text { surface }\end{array}$ \\
\cline { 2 - 4 } & 4 & Compression Plate & $\begin{array}{c}\text { Flexible plate to compress disk } \\
\text { springs }\end{array}$ \\
\cline { 2 - 4 } & 5 & Spherical Washer & Maintain bolt alignment \\
\hline
\end{tabular}
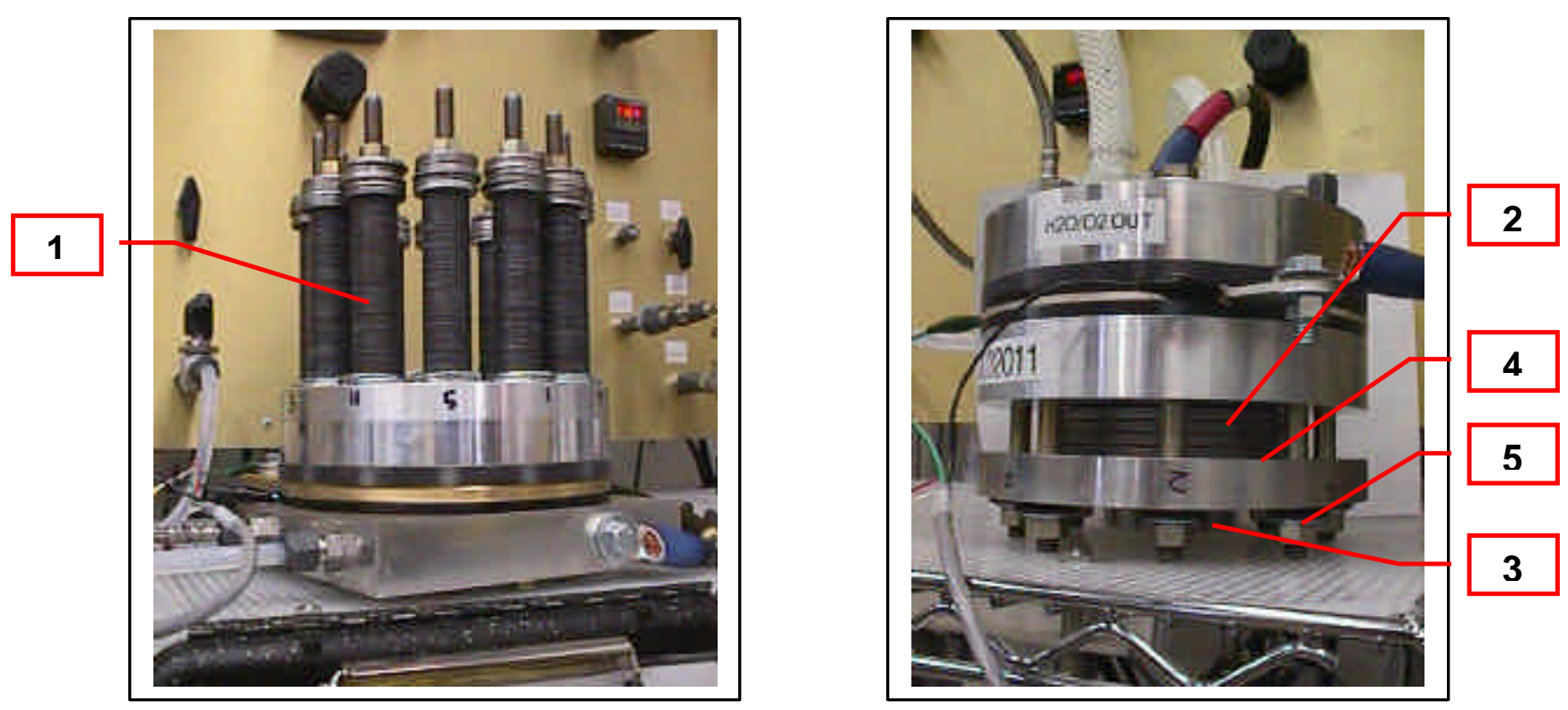

Figure 6-1 - Stack Compression Configurations

By going to the larger disk springs the assembly time for the stack is reduced from 75 minutes to 5 minutes, and the part count is reduced from 1344 pieces to 15 . Aside from the considerable assembly savings there is a tremendous improvement in quality. Each of the small spring washers must be oriented in a certain stacking configuration on each rod. This not only takes time but also has shown to be an easy place to have errors in assembly. These errors may manifest themselves in inconsistent loading across the cell stack causing potential sealing problems or even causing potential damage to the cell stack during operation.

In addition to the manufacturing savings in terms of assembly time, this new configuration also showed more uniform sealing across the face of the stack which could lead to better efficiency during operation of the cell stack. Lastly, the small envelope is much easier to package and handle when assembling into the final product and can potentially help to reduce the overall envelope of the product allowing further savings in sheet metal reduction. 


\subsection{Reductions in Catalyst Loadings}

For all PEM forms of electrolyzers and fuel cells, the cost of the membrane and electrode assembly (MEA) eventually becomes significant in the quest to reduce the overall cost of the system. Considering the electrolyzer as an entire system, the MEA cost (material and direct labor) today is less than $7 \%$ of the total cost of the product. So, while many other parts of the system have a greater impact on the total cost today, the MEA needs to be looked at since its relative cost as a percentage of the overall system will continue to increase as other costs fall. In addition, the parts that make up the MEA (i.e. membrane and precious metal catalysts) do not easily scale down in cost as volumes increase.

When considering lower catalyst loadings, the relative performance degradation that may be experienced needs to be weighed against the potential cost savings that could be realized. To adequately begin to investigate this, the following approach was undertaken. Prepare a set of MEAs with the "standard" anode catalyst loading while reducing the loading on the cathode. Then prepare a second set of MEAs with the "standard" cathode catalyst loading while reducing the anode loading. Evaluate each of these MEAs in standard test hardware to determine electrolyzer performance as a function of catalyst loading.

MEAs were prepared using Proton's standard catalyst materials and fabrication procedures in accordance with the test matrix outlined below in Figure 6-2. These MEAs were $0.03 \mathrm{ft}^{2}$ in area and used standard $0.03 \mathrm{ft}^{2}$ cell hardware for the evaluation. This hardware was chosen in order to conserve materials, for ease of assembly/disassembly, and testing. Single cells were built incorporating each of the test MEAs. An existing test stand was modified to accept these cells. Four cells were tested in parallel, each having their own power supply, water loop, and reservoir.

The MEA test protocol involved recording an initial polarization curve (current vs. voltage, i-v), followed by operation at constant current load of 28 A (approx. 900 $\mathrm{mA} / \mathrm{cm}^{2}$ ) for 100 hours. At that time another polarization curve was to be recorded. Selected MEAs could have been operated for longer periods of time (up to 2000 hours) in order to verify longer term performance and identify any voltage degradation trends. Specific performance metrics were to be identified from both the polarization data (e.g. current density@1.4 V, voltage at $500 \mathrm{~mA} / \mathrm{cm}^{2}$, max current density, etc.) and the life testing (e.g. voltage@ $\mathrm{t}=0 \mathrm{~h}, \mathrm{t}=100 \mathrm{~h}$, degradation rate $(\mu \mathrm{V} / \mathrm{h}))$ such that the MEA configurations can be compared. The results of this testing were to be tabulated in order to determine an optimum catalyst loading versus operating performance for both the cathode and anode catalyst. 


\begin{tabular}{|c|c|c|c|c|c|}
\hline \multirow{2}{*}{$\begin{array}{c}\text { Cathode }\left(\mathrm{H}_{2}\right) \\
\text { Loading } \\
\left(\mathrm{mg} \text { of } \mathrm{Pt} / \mathrm{cm}^{2}\right)\end{array}$} & \multicolumn{5}{|c|}{ Anode $\left(\mathrm{O}_{2}\right)$ Loading $\left(\mathrm{mg} \mathrm{Pt} / \mathrm{cm}^{2}\right)$} \\
\hline & $\mathrm{X}$ & $0.7 \mathrm{X}$ & $0.5 \mathrm{X}$ & $0.2 \mathrm{X}$ & $0.1 \mathrm{X}$ \\
\hline $\mathrm{Y}$ & Baseline & $?$ & $?$ & $?$ & $?$ \\
\hline $0.5 \mathrm{Y}$ & $?$ & & & & \\
\hline $0.3 \mathrm{Y}$ & $?$ & & & & \\
\hline $0.1 \mathrm{Y}$ & $?$ & & & & \\
\hline
\end{tabular}

Figure 6-2 - Catalyst Loading Test Matrix

The results shown in the polarization curves in Figure 6-3 indicate that reducing the catalyst loadings on the cathode side of the MEA have less of an impact then reducing the anode catalyst loadings as current density increases. At the low end (less than 200 ASF) of the current-voltage curve, there is little difference seen in MEA catalytic activity except for MEAs with the greatest reduction in loadings. This result is promising towards the goal of significantly reducing catalyst loadings. At higher current densities ohmic losses are more significant for the lower loading MEAs, which may be indicative of higher resistance in the catalyst layers due to less catalyst particle-particle contact. Future work on better electrode structures for the lower catalyst loadings is needed to address this deficiency.

Both anode and cathode catalyst loading amounts are important in the overall cost reduction approach needed for the product and additional testing will be undertaken on internally funding to attempt to alter the formulation and amounts of the anode loading to duplicate the good results achieved on the cathode side. Additional life data on full size cell stacks and larger active area stacks need to be collected and analyzed prior to considering incorporation of these MEA configurations into a product, but the initial results are promising. 
TDDR03001

February 2003

Polarization Curves for Various Cathode Loadings at 100 hours

$\mathrm{T}_{\text {INLET H2O }}=100^{\circ} \mathrm{F}, \mathrm{P}=45 / 0 \mathrm{psig}_{2} / \mathrm{O}_{2}$, @ Constant Anode Loading

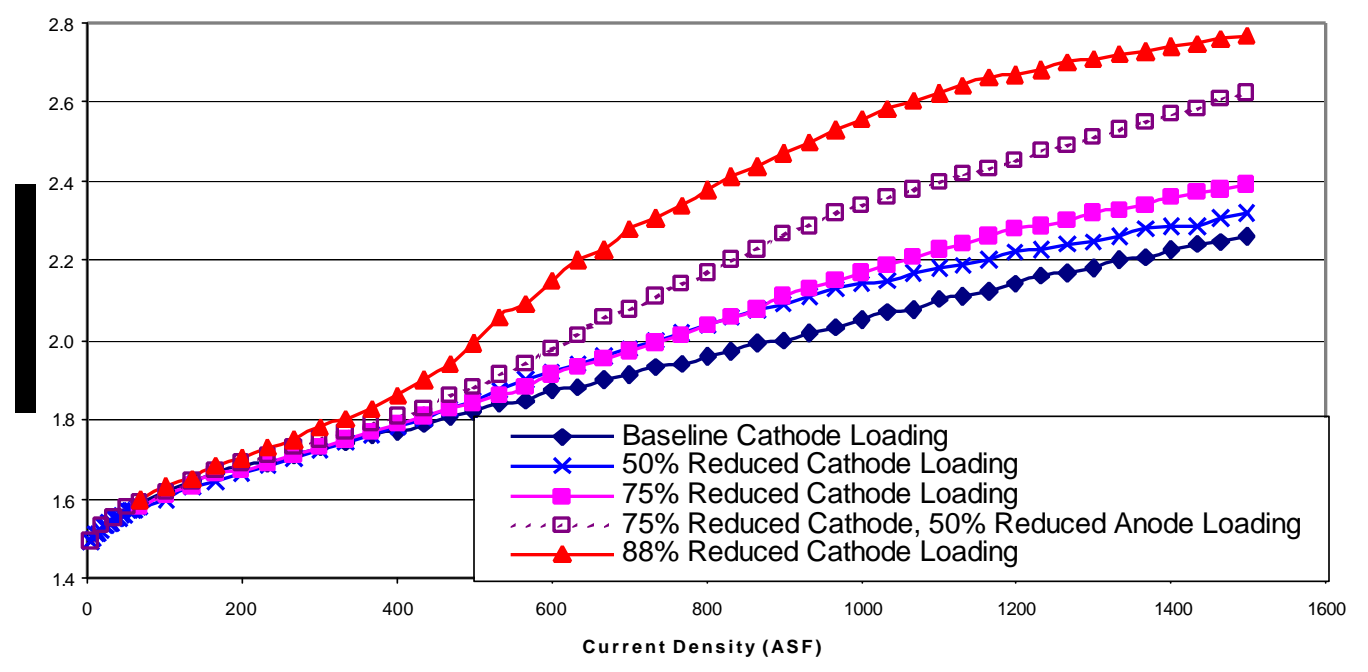

Durability Testing of Low Cathode Catalyst Loading MEAs

$T_{\text {INLET H2O }}=100 \circ \mathrm{F}, \mathrm{P}=45 / 0$ psig H2/O2, CD=933 ASF

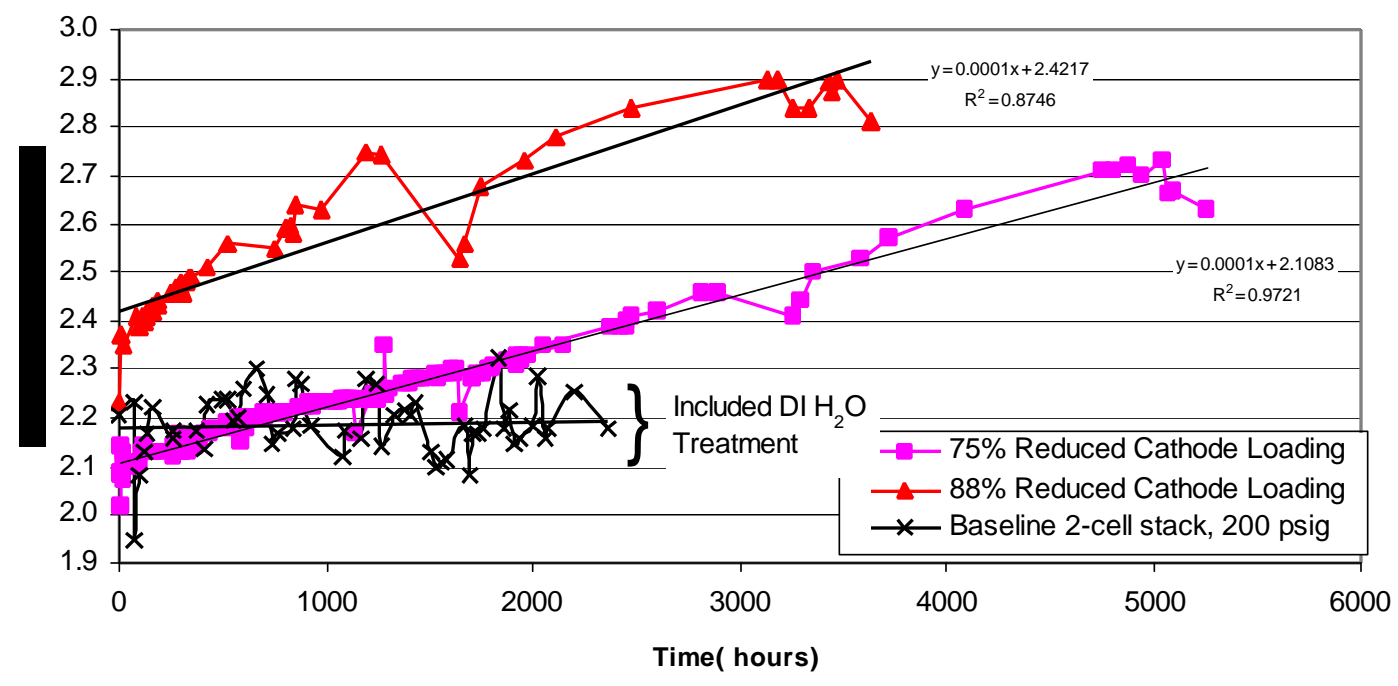

Figure 6-3 - Polarization Curves Showing Test Results

\subsection{Materials Research}

The materials of construction inside the cell stack are crucial to the life and performance that can be expected from the product. The rich hydrogen and oxygen atmosphere can destroy common materials quickly and is a leading cause of premature failure in 
electrolysis stacks historically. Under the program stainless steel 316L material was tested using a variety of coatings to characterize life. The coatings under consideration included TiCN, TiN, and Ta. Each of the parts was characterized for compatibility within the environment present in the electrolyzer and also on the basis of cost. The coatings were applied using a plasma vapor deposition technique (PVD). This is a commercial technique commonly used and the parts were manufactured with no problems encountered. The costs for the parts varied with TiCN being the highest option as compared to present materials and coatings in the cell stack today.

Testing of these materials did not begin until the fall of 2002. Some preliminary results showed that the coatings did not hold up very well in the cell stack environment. The coatings flaked off the parts easily when touched and the cell potential was higher then expected. Additional testing is still in process on these and other types of materials and further development into alternate material pathways will be necessary to fully characterize and develop confidence in low cost material paths for the cell stack.

\subsection{Statistical Variation Study}

When parts are manufactured in small batches under highly controlled conditions, it is relatively easy to minimize variation in part uniformity. Furthermore, matching of parts and hand sorting can be used such that any noticeable variation in part thickness or other tolerance parameters can be handled with relative ease. Once the part processing needs to be scaled up to a higher volume and the skill levels of the operators need to be decreased due to cost reasons, the statistical variation and process capability of the suppliers and internal processes must be fully known and tightly controlled.

A series of different parts from the HOGEN 40 hydrogen generator cell stack design were measured for a statistical analysis for the thickness dimensions. As would be expected some of the parts were better controlled than others. The analysis concluded that detailed reviews of supplier processes and specifications of materials would be required as well as incorporating more rigorous statistical process control in the processes. Figure 6-4 below summarizes the results of various materials. 
TDDR03001

February 2003

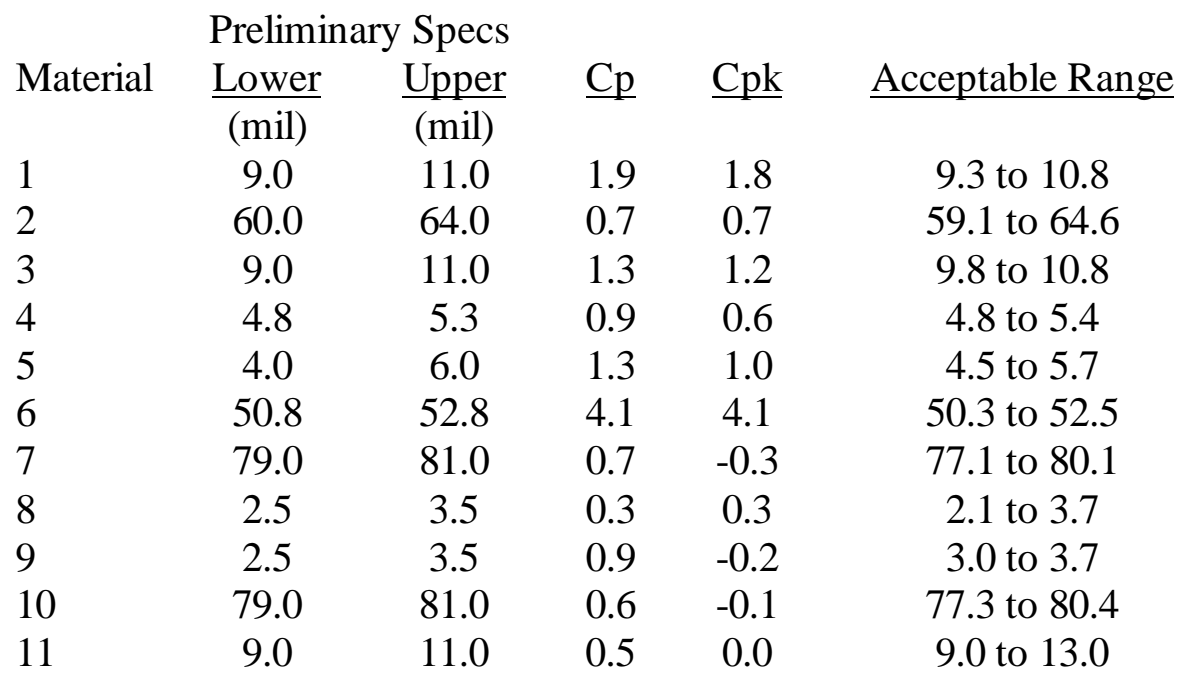

Figure 6-4 - Statistical Thickness Analysis of Various Component Materials

The $\mathrm{Cp}$ analysis of thickness variation compared to the specifications indicates that the majority of the parts come from sources that are capable of supplying a consistent product. However, it is unknown where the specifications supplied by Proton fall in the capability range of the suppliers process. In other words, the supplier may be capable of supplying the part to the specification requested, but the cost and yield associated with meeting the specification may be on the edge of the process capability. Further investigation into working with the suppliers in jointly developing specifications is the quickest route to the highest part quality at the lowest total cost.

A Cpk that is significantly lower than 1.0 while $\mathrm{Cp}$ is close to 1.0 or greater indicates a consistent product that lacks being centered around a target value. This occurred frequently in the analysis. The action that results from this is most often a review of the part's thickness variation and a determination of the adequacy of the component as manufactured. If so, a new target equal to the mean and new specifications equal to the mean $+/$ - three standard deviations are recommended. In the case where the part deviation is not acceptable, fabrication methodology, supply chain sourcing and concurrent development with the supplier may be required. In all cases, the supplier should be brought into the discussions to facilitate the process and arrive at the optimum solution. 


\section{Summary}

In less than two years, significant progress has been made in engineering cost reduced solutions that take a commercial and practical approach to PEM electrolyzer hardware. Developed in the 1950's, this technology has a long history in aerospace and military applications. Commercializing this technology is difficult and time consuming because the reliability expectations for the product are extremely high and cost reductions in critical components like the cell stack must be tested for long periods of time. While some applications have life requirements of five thousand or ten thousand hours, many have expectations of over thirty thousand hours.

Today, the HOGEN 40 hydrogen generator is equipped with a power converter that can handle renewable inputs, has components that will scale down commercially with volume production, is easy to assemble even at low volumes, and is ready to meet the technical and reliability challenges of industrial, renewable, and power markets.

The Department of Energy set out a goal for this program to produce an electrolyzer at this size, which can be manufactured for $\$ 1,000$ per $\mathrm{kW}$ (electrical power in) in quantities of 10,000 units per year. While some of the cell stack material advances needed to solidify this pathway are still undergoing life and durability testing, the overall goal is within sight. Confidence is high that as these markets develop, PEM electrolyzers will prove to be a reliable and cost effective solution to the world's hydrogen energy needs.

\section{References}

1. Friedland, R., Smith, W., Speranza, A., January 2000. Integrated Renewable Hydrogen Utility System, Phase I Final Technical Report and Market Assessment PES-T-99014.

2. Friedland, R., Speranza, A., May 2001. Hydrogen Production Through Electrolysis, Phase II Technical Paper for Annual Technical Peer Review.

3. Friedland, R., Speranza, A., June 2002. Hydrogen Production Through Electrolysis, Phase II Technical Paper for Annual Technical Peer Review. 